\title{
Carbon Nanofiber Reinforced and PU-toughened POM Ternary Composites: Friction, Wear and Creep Properties
}

\author{
Suchart Siengchin \\ Production Engineering Department \\ The Sirindhorn International Thai-German Graduate School of Engineering (TGGS) \\ King Mongkut's University of Technology North Bangkok \\ 1518 Pibulsongkram Road, Bangsue, Bangkok 10800, Thailand \\ E-mail: suchart.s.pe@tggs-bangkok.org
}

Received: October 17, 2011 Accepted: October 27, $2011 \quad$ Published: December 31, 2011

doi:10.5539/mer.v1n1p69 URL: http://dx.doi.org/10.5539/mer.v1n1p69

\begin{abstract}
Composites composed of polyoxymethylene (POM), polyurethane (PU) and carbon nanofiber (CNF) were produced by water-mediated melt compounding. PU latex and/or aqueous CNF dispersion were introduced into the molten POM in laboratory kneader to prepare toughened and/or nanoreinforced POM composites. The dispersion of the CNF was inspected using scanning electron microscopy (SEM). The mechanical properties (friction, wear and creep strain) of the composites were determined by roller (steel)-on-plate (ROP) and creep tensile tests. It was found that CNF worked as a reinforcement and improved the coefficient of friction (COF) and wear. It was also found that, the creep resistance decreases with increasing time, temperature and addition of CNF.
\end{abstract}

Keywords: Nanocomposite, polyoxymethylene (POM), Carbon nanofiber (CNF), Polyurethane (PU), Creep, Friction, Wear

\section{Introduction}

The major problem with nanoparticles reinforcement is that it causes severe material embitterment which is in close analogy with discontinuous fiber-reinforced thermoplastics. Blending the thermoplastic with elastomeric modifiers is a successful way to overcome this problem and improve the toughness characteristics. Many papers have documented the effect of various modifier parameters on the toughness response including rubber particle size (Borggreve R.J.M., 1989; Margolina A. \& Wu S., 1988), rubber concentration (Borggreve R.J.M., 1989; Baldi, F., 2006) and interparticle distance (Wu S., 1988; Jiang, W., et al., 2002). These studies revealed that the rubber concentration should be above a critical level which is dependent on its particle size. To improve the toughness of a polymer, the interparticle distance should fall below a critical value which depends on the volume fraction and the particle size of the rubbers. Typical rubber particle sizes for effective toughening should be in the nano-scale range.

It has been shown in literature that the properties of polymers can be improved by adding carbon- nanofibers (CNFs) and nanotubes (CNTs) (Shokrieh M. M. \& Rafiee R., 2010). Most of CNF/CNT reinforced polymer composites show improvements in strength and stiffness with loss of elongation at break (Kumar, S., et al., 2002; Chung D.D.L., 2001; Sandler J., et al., 2002). However, a number of experimental studies reported in literature about the influence of CNT/CNF on the toughness enhancements, including wear resistance of various types of polymers (Puglia D., 2003; Song Y.S. \& Youn J.R., 2005; Kinloch, I.A., et al., 2002; Gryschuck O., 2006; Xu D., et al., 2009) . Ruan et al. (Ruan S.L., et al., 2003) showed enhancements in ductility of MWCNT/ reinforced ultrahigh molecular weight polyethylene (PE). The increased ductility in PE is most likely due to the chain mobility enhancement and attributed to the secondary crystal formation due to the presence of MWCNT. Lozano et al. [16] published extremely high extensibility; high toughness of CNF reinforced polyethylene bulk composites. The large ductility increase in PE has been attributed to the excellent dispersion of CNFs and interfacial bonding produced by the high shear history. Xu et al. (2009) investigated the friction and wear of HNBR with carbon black (CB) and MWCNT. They found that CB and MWCNT containing HNBR enhanced the wear and friction properties. Considerable interest has been devoted to nanocomposites due to their attractive 
properties. In particular the dielectric and mechanical properties of polymer based nanocomposites were markedly improved by the addition of CNF (Sui G., et al., 2008; Sui G., et al., 2009). Its presence in a small amount in the corresponding polymer, typically less than $5 \mathrm{wt}$ \% can result in significant improvement in mechanical properties. The amount of CNF and how it is distributed are key factors in respect to the reinforcing effect (Prolongo S.G., 2009). The length of CNF can vary in between 50-100 $\mu \mathrm{m}$, therefore high aspect ratios can be obtained. As previously reported, CNF were purified and functionalized to remove amorphous carbon and to open the highly tangled fiber (Lozano K., 1999). Being much longer than CNT, the disentanglement and-, dispersion of CNF is very problematic. Therefore, the goal of improving the carbon nanofiber matrix interfacial adhesion issue and complete dispersion must be solved before achieving the full potential of CNF nanocomposites.

Other techniques besides that of traditional melt compounding were also explored to improve the dispersion of nanofillers. For thermoplastics for example the water-mediated dispersion of suitable nanofillers has been developed (Siengchin S. \& Karger-Kocsis J., 2009). This is straightforward not only from the viewpoint of the dispersion of the nanofillers, but also in respect to health hazard issues. Accordingly, the goal of this present work was to explore further the potential of the water-mediated compounding using PU latex and/or aqueous CNFs dispersion, and study the structure, creep and dry sliding behaviors of the related composites.

\section{Experimental}

\subsection{Materials and preparation of composites}

Aqueous dispersion of CNF with a concentration of $15 \mathrm{~g} / \mathrm{L}$ was donated by Grupo Antolin (Burgos, Spain). The related CNF had a diameter range of $20-80 \mathrm{~nm}$, a graphitization degree of about $70 \mathrm{wt} . \%$, and a metallic particle content of 6-8 wt.\%. Although the length of the CNFs from Grupo Antolin is usually greater than $30 \mu \mathrm{m}$, no information was available on the aspect ratio of the CNF aqueous dispersion delivered. PU latex with 50 wt.\% dry content (Acralen U 550) which has the particles in the size range 100 to $1000 \mathrm{~nm}$ (according to suppliers' information), was supplied by Polymer Latex GmbH (Marl, Germany). Granulated POM (Hostaform C 9021, Ticona $\mathrm{GmbH}$, Frankfurt, Germany) was utilized as polymeric matrix for all composite systems. Its volumetric melt flow rate (MVR at $190^{\circ} \mathrm{C} / 2.16 \mathrm{~kg}$ ) was $8 \mathrm{~cm}^{3} / 10 \mathrm{~min}$.

$\mathrm{POM} / \mathrm{PU}$ blend, POM/CNF binary and $\mathrm{POM} / \mathrm{PU} / \mathrm{CNF}$ ternary nanocomposites were prepared by laboratory kneader (Type 50 of Brabender, Duisburg, Germany) at $\mathrm{T}=190^{\circ} \mathrm{C}$ and rotor speed of $60 \mathrm{rpm}$. The PU rubber particle and/or CNF contents in the system investigated (blend, binary and ternary composites) were set for 10 and 0.1 wt. \%, respectively. The aqueous dispersion of CNF and/or PU latex was dropped in the POM melt after its mastication for $2 \mathrm{~min}$. in the kneading chamber. The overall duration of the melt mixing for both binary and ternary nanocomposites was $6 \mathrm{~min}$. The compounds were compression molded into $1 \mathrm{~mm}$ thick sheets at $\mathrm{T}=200^{\circ} \mathrm{C}$ using a hot press (EP-Stanzteil, Wallenhorst, Germany).

\subsection{Morphology detection}

The dispersion of CNF in the POM nanocomposites was studied by scanning electron microscopy (SEM). The fracture surfaces of tensile loaded specimens were subjected to SEM inspection in a Supra ${ }^{\mathrm{TM}}$ 40VP SEM (Carl Zeiss GmbH, Oberkochen, Germany). The surface was carbon coated prior to SEM inspection performed at low acceleration voltage.

\subsection{Sliding friction and wear}

Friction and wear characteristics were determined using roller (steel)-on-plate (ROP) tests. The ROP test set-up is depicted schematically in Figure 1. A rotating steel roller $(9 \mathrm{SMnPb} 28 \mathrm{k}$, diameter: $10 \mathrm{~mm}$, width: $20 \mathrm{~mm}, \mathrm{Ra} \approx$ $0.9 \mu \mathrm{m}$ ) was pressed against a specimen strip of $9 \mathrm{~mm}$ width in a SOP 3000 tribotester (Dr Tillwich GmbH, Horb-Ahldorf, Germany). The friction force induced by the torque was measured online and thus the coefficient of friction (COF) was recorded during the test. The test parameters were a load of $50 \mathrm{~N}$, sliding speed of 250 $\mathrm{mm} / \mathrm{s}$ and duration of $2 \mathrm{~h}$.

The wear rates were determined by equation:

$$
W=\frac{\Delta m}{F_{N} \cdot L}
$$

Where $\Delta \mathrm{m}$ is the mass loss recorded gravimetrically, $\mathrm{FN}$ is the normal force and $\mathrm{L}$ is the overall sliding distance.

\subsection{Creep response}

The short time creep test was performed in tensile mode at different temperatures using the DMA Q800 
apparatus (TA Instruments, New Castle, NJ, USA). The applied tensile stress was $6 \mathrm{MPa}$. The temperature dependence of the creep response of $\mathrm{POM}$ and its composites was studied in the range from -50 to $80^{\circ} \mathrm{C}$. Isothermal tests were run on the same specimen in the above temperature range by increasing the temperature stepwise by $5^{\circ} \mathrm{C}$ and equilibrating the specimen at each temperature for $5 \mathrm{~min}$. During the isothermal tests the duration of the creep testing was $15 \mathrm{~min}$. The creep test was performed on dumbbell-shaped specimens (5B type according to DIN-EN ISO 527) by considering their rectangular section.

\section{Results and Discussion}

\subsection{Friction and wear}

Tribotest data in the form of wear rate is displayed in Figure 2. Due to the rubbery character of the incorporated $\mathrm{PU}$, the POM/PU blend exhibits a markedly higher wear rate than the neat POM. This increase is mainly due to the stress concentration effects of rubber particles which has lower stiffness difference between POM and PU. The small PU particles in range of 1-3 $\mu \mathrm{m}$, caused of the reduction in wear resistance, are obvious in Figure $3 \mathrm{a}$ based on SEM analysis. The effect of CNF on the wear rate is demonstrated on example of the POM/CNF and $\mathrm{POM} / \mathrm{PU} / \mathrm{CNF}$ blend also in this Figure. One can recognize that filled CNF in POM or POM/PU blend improved the rolling wear resistance. The enhancement in wear rate of nanocomposites containing $0.1 \mathrm{wt}$ \% CNF was ca. $14 \%$ compared to the neat POM and POM/PU blend. This suggests that due to the work of uniform CNF dispersion as reinforcement in the POM matrix, an efficient load transfer occurs from POM, even POM/PU blend toward the CNF which can reduce the shear stress during sliding. SEM pictures confirm that the CNF is homogeneous dispersed in POM (cf. Figure 3b). High magnification SEM picture (cf. Figure 3c) may hints for CNF effect of locally in the POM region and had high aspect ratio.

The coefficient of friction (COF) as a function of time is shown for the POM, POM/CNF, POM/PU and $\mathrm{POM} / \mathrm{PU} / \mathrm{CNF}$ composites in Figure 4. One can notice that the COF as function of time undergoes a step-like transition with increasing time for POM/PU and POM/PU/CNF. The POM and the POM/CNF composite exhibit two step-like transitions at least. Incorporation of CNF in POM matrix is effective in keeping the frictional coefficient very low within the initial period whereas additional PU particles increase COF in the whole range. Accordingly, the COF of binary-, and ternary composites was remarkably improved by additional CNF, which is consistent with our wear resistance observations. So in case, the COF of POM/CNF composite compared to neat POM was reduced from 0.38 to 0.35 when running in steady state sliding stage. In order to consider eventual changes in the crystalline structure of POM on the COF response, it has been reported that incorporation of CNF increases the crystallinity of POM. As a consequence, the COF response may not always enhanced by addition of $\mathrm{CNF}$ and a fine dispersion. However, it can be also deteriorated may due to improved crystallinity as reported in a previous paper (Siengchin, S., et al., 2010).

\subsection{Creep strain}

The viscoelastic behavior of related composites is usually characterized in creep test (whereby the creep strain is measured in time under a constant load). In the nonlinear range the dependence upon the level of the applied load can be expressed by multiplying the linear parameters by so-called nonlinearity factors, which are load, time and temperature dependent. The nonlinear creep compliance is given by:

$$
D(t, \sigma(t), T)=\frac{\varepsilon(t, \sigma(t), T)}{\sigma_{0}}
$$

Where $\sigma(t)$ is the real stress at time, $t$ and $\mathrm{T}$ is temperature. This equation can be expressed simplified with:

$$
\varepsilon(t, \sigma(t), T)=\varepsilon\left(t, \sigma_{0}, T\right)=\varepsilon(t, T) c \sigma_{0}
$$

Thus, the following equation can be also expressed in terms of creep compliance.

$$
D(t, \sigma(t), T)=D\left(t, \sigma_{0}, T\right)=c \varepsilon(t, T)
$$

Where $\mathrm{c}$ is a constant. In the above equation, creep compliance is only a function of the time and temperature.

Significant reinforcement of adding lower CNF concentration was achieved by tensile mechanical characteristics as observed from considerable increase in tensile strength and stiffness, while the elongation at break reduced by CNF incorporation. The use of PU resulted in respect to improve the ductility (Siengchin, S., et al., 2010). 
Generally, the toughness of composite materials can be related to the creep properties. Recall, CNF reinforced and PU toughened POM is such a material that which is easily susceptible to creep analysis is an alternative method for the effective production of POM/PU/CNF composite.

Figures 5a-5d, demonstrate the effects of increased temperature on the creep strain of CNF systems studied. Creep strain refers to the time-dependent viscoelastic flow occurring in composites based on semi-crystalline POM matrix under the action of an applied load at elevated temperatures. It is well documented that the two distinct stages of flow within the creep curves generally can be identified. Thus, there is a normal primary stage in which the strain rate decreases with increasing time, a brief secondary stage where the strain rate remains reasonably constant. The shape of creep strain curves of CNF composites and blend is similar to that of neat POM from low temperature up to $25^{\circ} \mathrm{C}$. One can notice that observed at ambient temperature is assigned to the motions of long molecular segments of POM in disordered and well-ordered crystalline phases, lies still at a low value of obtained creep strain and present a plateau creep strain that is time independent. As expected, at high temperature the molecular mobility was highly thermally activated and become rubbery status of time dependent. The accelerating movement of amorphous chains increases again with increasing time.

The composites based on POM matrix exhibited different creep strain at elevated temperatures, indicating that CNF with changed amorphous structures and crystalline morphology had diverse response to temperature. The creep strain decreased remarkably with the incorporation of CNF compared to POM and POM/PU blend (cf. Figure $5 \mathrm{a}$ and $5 \mathrm{c}$, respectively). The presence of PU particles increases the creep strain rate $(d \varepsilon / d t)$. The increment in the creep strain by adding PU is due to chain flexibilization $\left(-50^{\circ} \mathrm{C} \mathrm{Tg}\right.$ of PU according to Ref. 23) also to the fine dispersion of rubbery character (cf. Figure 3a). It should be noted that this effect is suppressed in the low CNF-containing composites due to a homogeneous CNF dispersion (cf. Figure 3b). The reinforcing effect of CNF suggests also hindered segmental motion in the boundary amorphous layers of crystals. The related results also confirmed that the long CNF relive very strongly reinforcing effect in agreement with the Tribotest (cf. Figure 2 and 4). However, additional CNF become quite effective in the higher temperature range. This enhancement contributed to efficient load transfer between CNF and surrounding POM chains over the ambient temperature. Moreover, this finding indicates that the creep rate process under high temperature in restricted the amorphous segments was significantly constrained by the presence of CNF. The creep mechanisms of the molecular structure that represents $\mathrm{POM} / \mathrm{CNF}$ composite, supposed to be work under constant loading, are summarized in Figure 6 schematically. Under a constant tensile load, the amorphous molecular structure of POM is difficultly susceptible to polymer molecules untangling and slipping by each other due to CNF restricting with inter-molecular. The crystalline molecular structure of POM has a stronger and denser bond. It is susceptible to tilting and reorienting, as well as slight and rotation. All these responses of the POM/CNF composite are dependent on time and temperature. However, the creep strain reduction of increased temperature and time of creep strain can be explained by considering the delay of rotation and separation mechanisms in respect to the CNF reinforcement. Note that CNF reinforcing the matrix in POM system, increase creep resistance.

\section{Conclusion}

In this work, $\mathrm{POM} / \mathrm{CNF}, \mathrm{POM} / \mathrm{PU}$ and $\mathrm{POM} / \mathrm{PU} / \mathrm{CNF}$ systems using PU latex and aqueous $\mathrm{CNF}$ dispersion were produced by water-mediated melt blending technique. The morphology, sliding wear, coefficient of friction (COF) and creep properties of the binary and ternary systems were studied. SEM proved a uniform distribution of the CNF in POM. The wear resistance, COF and creep resistance behaviors of POM were improved by CNF incorporation. CNF worked as a reinforcing action when introduced into the POM/PU blend. These related behaviors were suggested to be controlled by CNF-homogeneous dispersion. A similar trend of wear properties has been reported for MWCT/HNBR composite and low concentration of CNF/ ultra-high molecular weight polyethylene (UHMWPE) matrix (Xu D., et al., 2009; Wood W.J., et al., 2011).

This work was performed in the framework of a bilateral collaboration between the Thailand and Germany.

\section{References}

Baldi F., Bignotti F., Tieghi G., \& Riccó T. (2006). Rubber toughening of polyamide 6/organoclay nanocomposites obtained by melt blending. J. Appl. Polym. Sci., 99, 3406-3416. http://dx.doi.org/ 10.1002/app.23804

Borggreve R. J. M., Gaymans R. J., \& Schuijer J. (1989). Impact behaviour of nylon-rubber blends: 5. Influence of the mechanical properties of the elastomer. Polymer, 30, 71-77. http://dx.doi.org/10.1016/0032-3861(89)90385-6

Chung D. D. L. (2001). Comparison of submicron-diameter carbon filaments and conventional carbon fibers as 
fillers in composite materials. Carbon, 39, 1119-1125. http://dx.doi.org/ 10.1016/S0008-6223(00)00314-6

Gryschuck O., Karger-Kocsis J., Thomann R., Kanya Z., \& Kiricsi I. (2006). Multiwall carbon nanotube modified vinylester and vinylester - based hybrid resins. Composites Part A, 37, 1252-1259. http://dx.doi.org/10.1016/j.compositesa.2005.09.003

Jiang W., Yuan Q., An L., \& Jiang B. (2002). Effect of cavitations on brittle-ductile transition of particle toughened thermoplastic. Polym. Commun., 43, 1555-1558. http://dx.doi.org/10.1016/S0032-3861(01)00676-0

Karger-Kocsis J., Felhõs D., Bárány T., \& Czigány T. (2008). Hybrids of HNBR and in situ polymerizable cyclic butylenes terephthalate (CBT) oligomers: properties and dry sliding behavior. eXPRESS Polym. Letters, 2, 520-527. http://dx.doi.org/ 10.3144/expresspolymlett.2008.62

Kinloch I.A., Roberts S. A., \& Windle A. H. (2002). A rheological study of concentrated aqueous nanotube dispersions. Polymer, 43, 7483-7491. http://dx.doi.org/ 10.1016/S0032-3861(02)00664-X

Kumar S., Doshi H., Srinivasarao M., Park J.O., \& Schiraldi, D.A. (2002). Fibers from polypropylene/nano carbon fiber composites. Polymer, 43, 1701-1703. http://dx.doi.org/10.1016/S0032-3861(01)00744-3

Lozano K., Files B., Rodriguez-Macias F., \& Barrera E. V. (1999). Purification and functionalization of vapor grown carbon fibers and single wall nanotubes, Symposium Powder Materials: Current Research and Industrial Practices, Cincinnati OH, USA, TMS fall meeting, pp. 333-340.

Lozano K., Yang S., \& Jones R. E. (2004). Nanofiber toughened polyethylene composites. Carbon, 42, 2329-2331. http://dx.doi.org/10.1016/j.carbon.2004.03.021

Margolina A., \& Wu S. (1988). Percolation model for brittle-tough transition in nylon/rubber blends. Polymer, 29, 2170-2173. http://dx.doi.org/10.1016/0032-3861(88)90108-5

Prolongo S. G., Campo M., Gude M. R., Chaos-Morán R., \& Ureña A. (2009). Thermo-physical characterisation of epoxy resin reinforced by amino-functionalized carbon nanofibers. Compos. Sci. Techn., 69, 349-357. http://dx.doi.org/ 10.1016/j.compscitech.2008.10.018

Puglia D., Valentine L., \& Kenny J. M. (2003). Analysis of the cure reaction of carbon nanotubes/epoxy resin composites through thermal analysis and Raman spectroscopy. J. Appl. Polym. Sci., 88, 452-458. http://dx.doi.org/10.1002/app.11745

Ruan S. L., Gao P., Yang X. G., \& Yu T. X. (2003). Toughening high performance unltrahigh molecular weight polyethylene using multiwalled carbon nanotubes. Polymer, 44, 5643-5654. http://dx.doi.org/10.1016/S0032-3861(03)00628-1

Sandler J., Werner P., Shaffer M. S. P., Demchuk V., Altstaedt V., \& Windle A. H. (2002). Carbon nanofibre reinforced poly (ether ether ketone) composites. Composites Part A, 33, 1033-1039. http://dx.doi.org/10.1016/S1359-835X(02)00084-2

Shokrieh M. M., \& Rafiee R. (2010). A review of the mechnical properties of isolated carbon nanotubes and carbon nanotube composites. Mech. Compos. Mater., 46, 155-172. http://dx.doi.org/ 10.1007/s11029-010-9135-0

Siengchin S., \& Karger-Kocsis J. (2009). Structure and creep response of toughened and nanoreinforced polyamides produced via the latex route: effect of nanofiller type. Comp. Sci. Tech., 69, 677-683. http://dx.doi.org/ 10.1016/j.compscitech.2009.01.003

Siengchin S., Psarras G.C., \& Karger-Kocsis J. (2010). POM/PU/carbon nanofiber composites produced by water-mediated melt compounding: structure, thermomechanical and dielectrical properties. J. Appl. Polym. Sci., 117, 1804-1812. http://dx.doi.org/ 10.1002/app.32133

Song Y. S., \& Youn J. R. (2005) .Influence of dispersion states of carbon nanotubes on physical properties of epoxy nanocomposites. Carbon, 43, 1378-1385. http://dx.doi.org/10.1016/j.carbon.2005.01.007

Sui G., Jana S., Zhong W. H., Fuqua M. A., \& Ulven C.A. (2008). Dielectric properties and conductivity of carbon nanofiber/semi-crystalline polymer composites. Acta Materialia, 56, 2381-2388. http://dx.doi.org/10.1016/j.actamat.2008.01.034

Sui G., Zhong W. H., Ren X., Wang X. Q., \& Yang X.P. (2009). Structure, mechanical properties and friction behavior of UHMWPE/HDPE/carbon nanofibers. Mater. Chem. Phys., 115, 404-412. http://dx.doi.org/10.1016/j.matchemphys.2008.12.016

Wood W. J., Maguire R. G., \& Zhong W. H. (2011). Improved wear and mechanical properties of UHMWPE-carbon nanofiber composites through an optimized paraffin-assisted melt-mixing process. Compos. 
Part B, 42, 584-591. http://dx.doi.org/10.1016/j.compositesb.2010.09.006

Wu S. (1988). A generalized criterion for rubber toughening: The critical matrix ligament thickness. J. Appl. Polym. Sci., 35, 549-561. http://dx.doi.org/10.1002/app.1988.070350220

Xu D., Karger-Kocsis J., \& Schlarb A. K. (2009). Friction and wear of HNBR with different fillers under dry rolling and sliding conditions. eXPRESS Polym. Letters, 3, 126-136. http://dx.doi.org/10.3144/expresspolymlett.2009.16

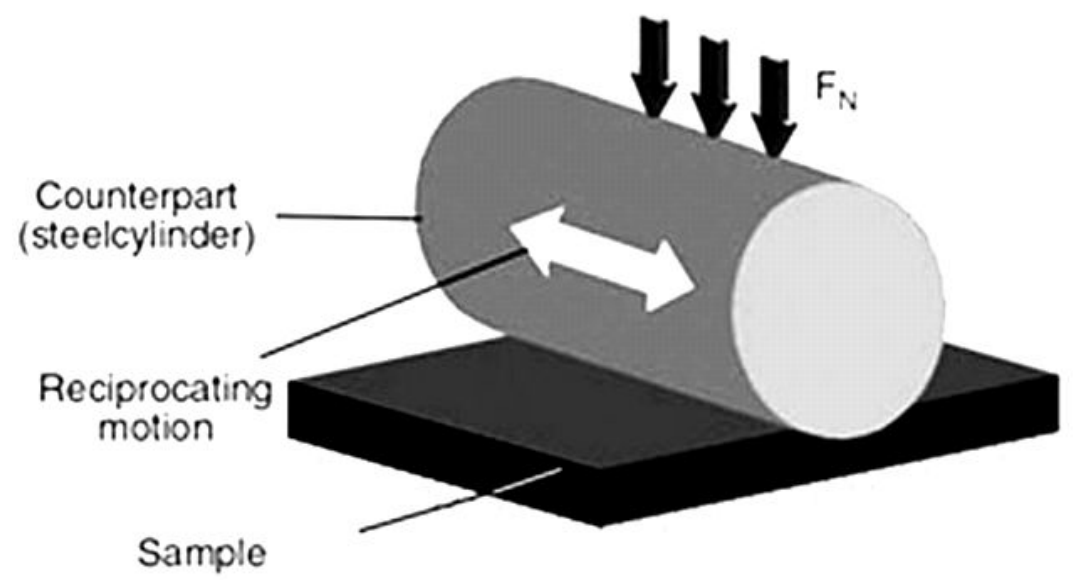

Figure 1. Schematic set-up of the roller(steel) on plate (ROP) (Karger-Kocsis J., et al., 2008)

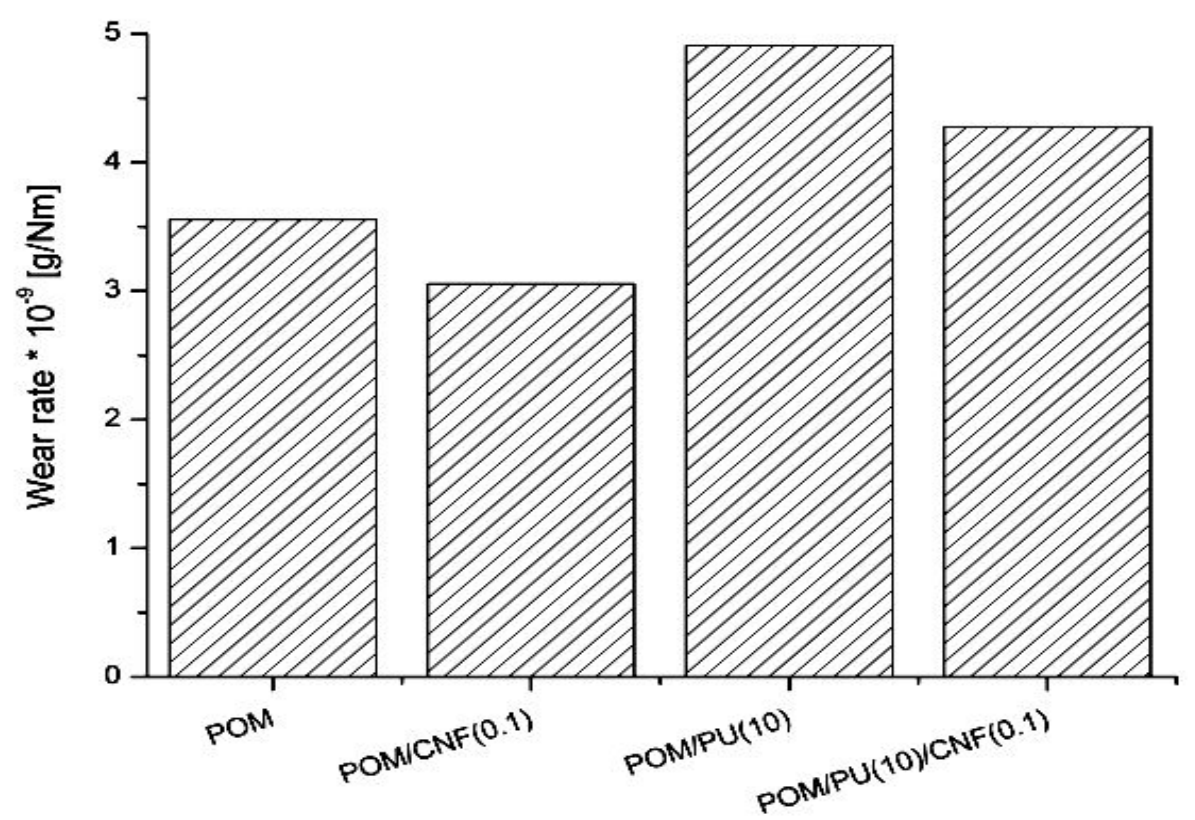

Figure 2. Wear rate data of the CNF systems studied 


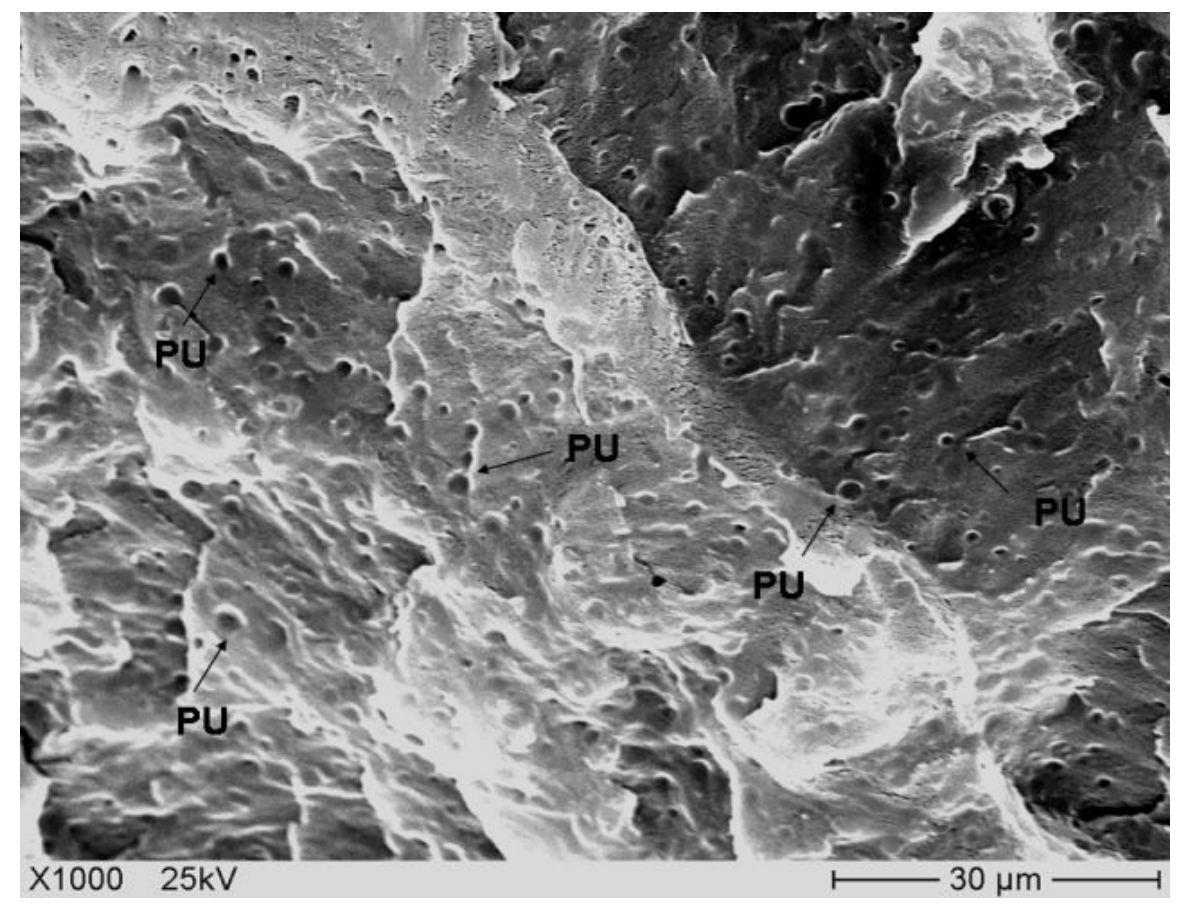

3a)

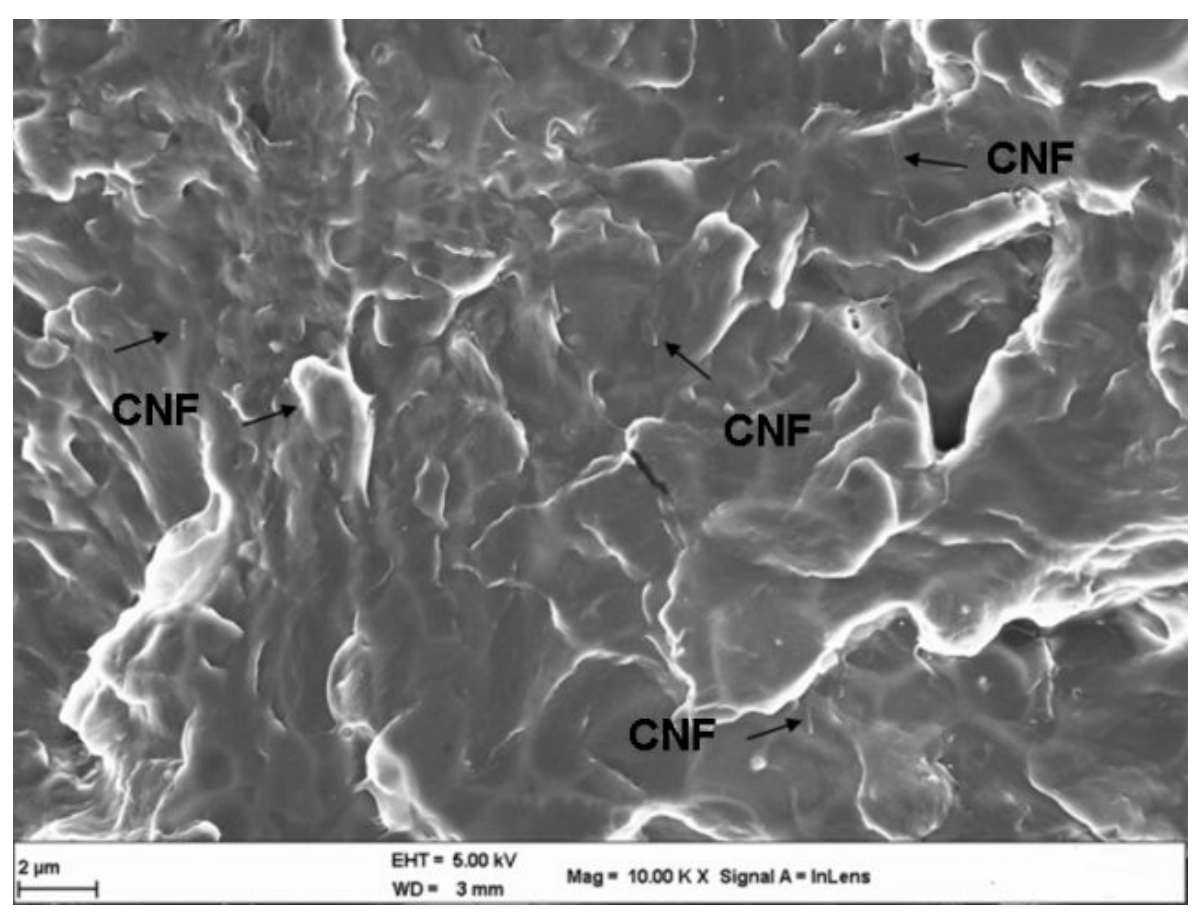

3b) 


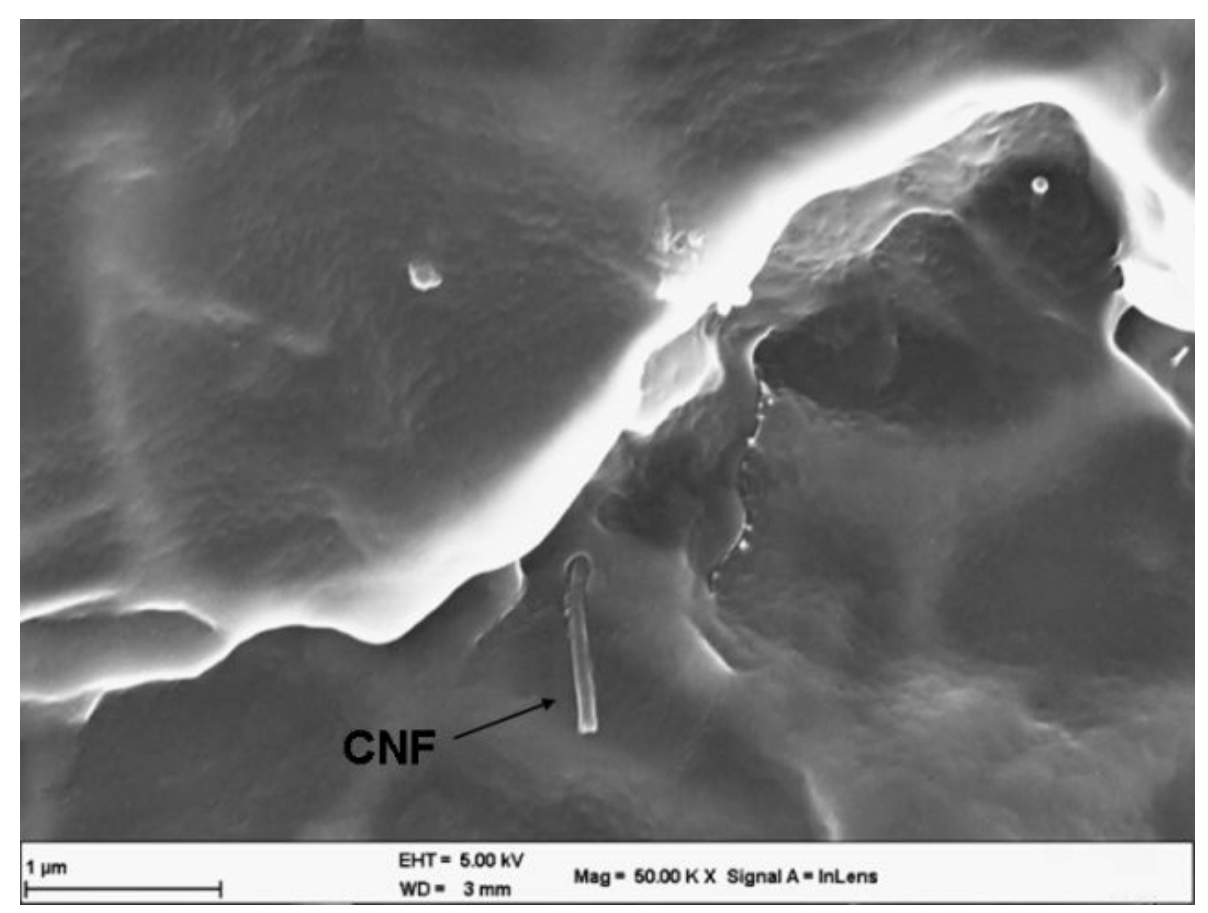

$3 c)$

Figure 3. SEM pictures taken from POM/PU(10 wt.\%); a) and POM containing $0.1 \mathrm{wt} . \% \mathrm{CNFs}$ of magnification b) $-\mathrm{x} 10000$ and c) $-\mathrm{x} 50000$ (Note: Arrow indicates CNF)

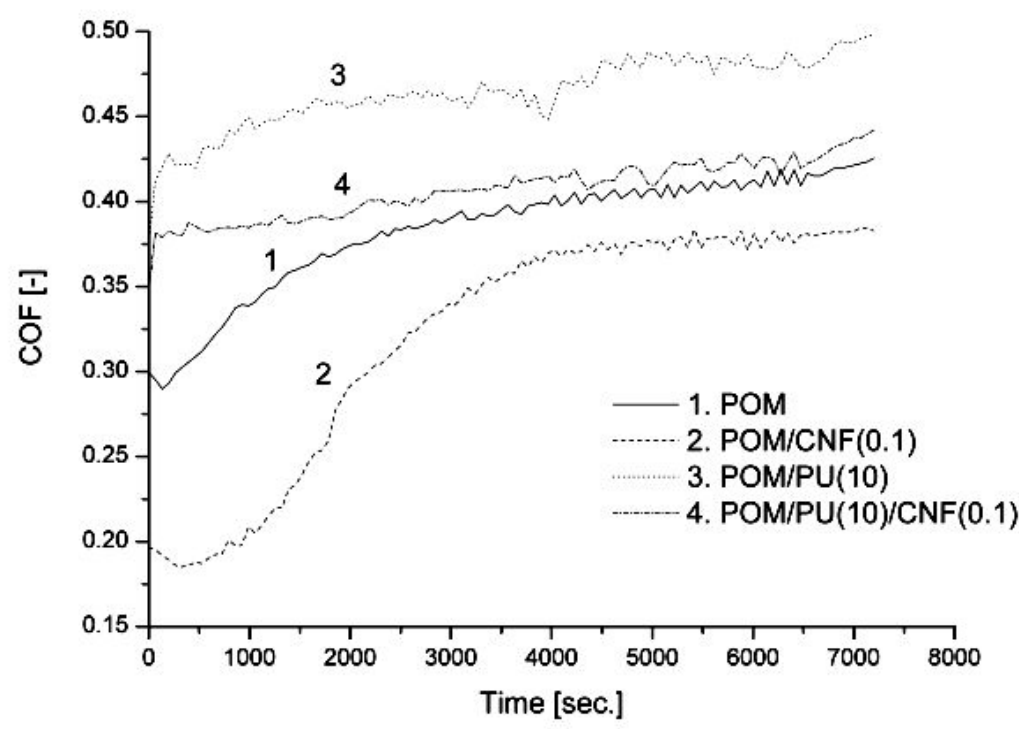

Figure 4. Coefficient of friction vs. time for POM, POM/CNF, POM/PU and POM/PU/CNF 


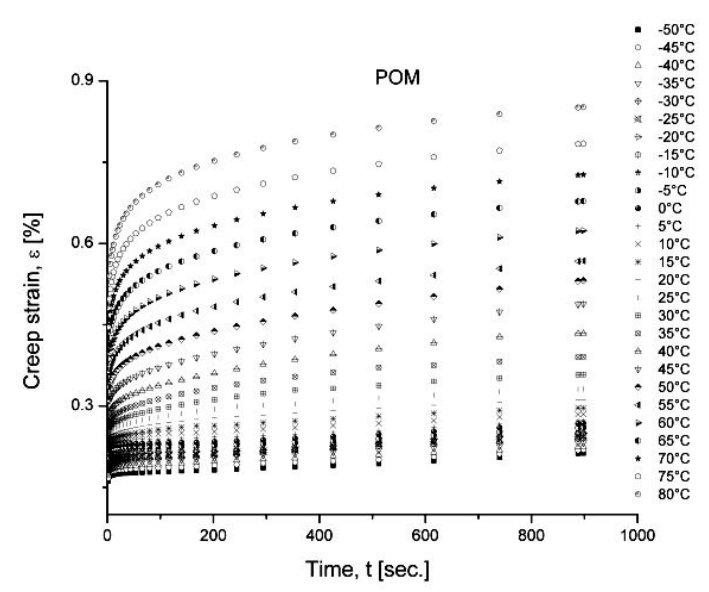

5a)

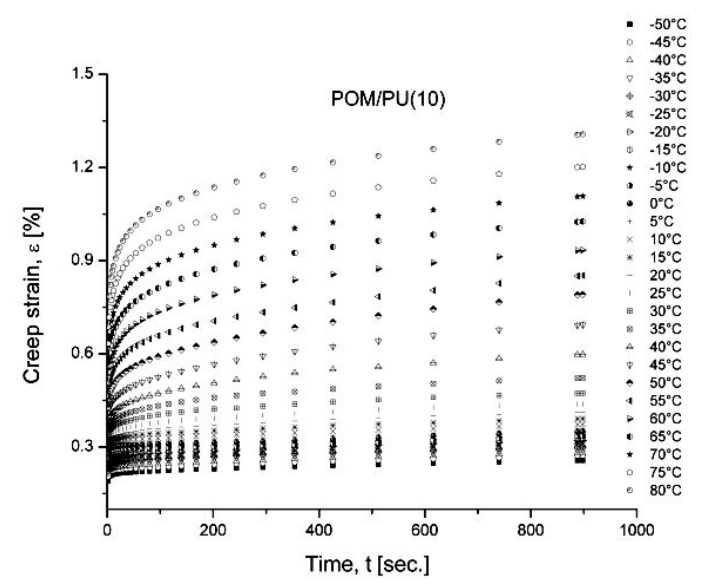

5c)

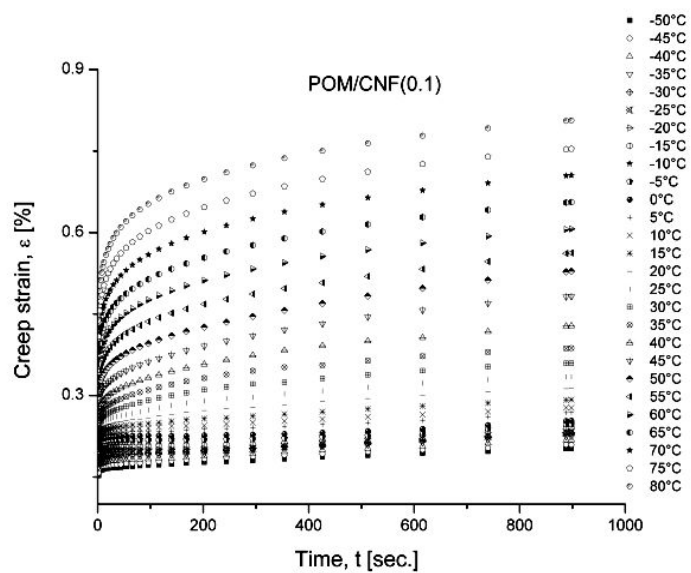

5b)

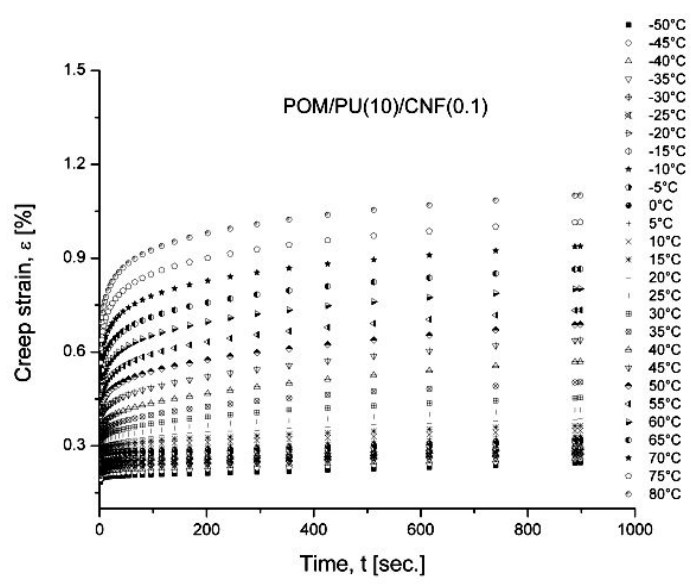

5d)

Figure 5. Effect of temperature on the tensile creep strain of POM (a), POM/CNF (b) POM/PU blend (c) and $\mathrm{POM} / \mathrm{PU} / \mathrm{CNF}$ composite (d) 


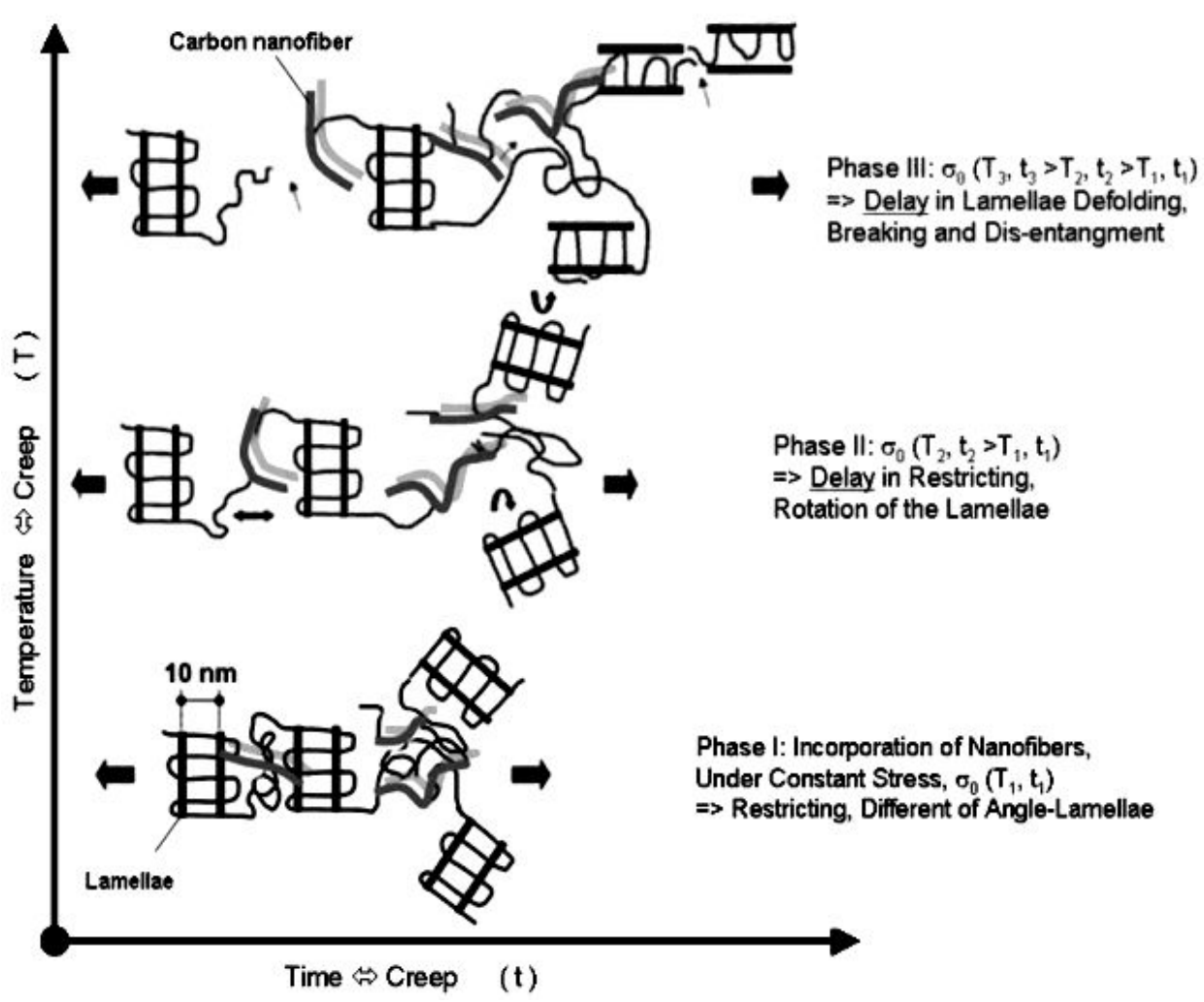

Figure 6. Schemes of the Reinforcing effect of CNF by increasing of temperature and time 